\title{
Management Accounting and the Control of Organizational Performance
}

\author{
$\mathrm{Hao} \mathrm{Wu}^{1}$ \\ ${ }^{1}$ Cardiff University, Cardiff, Wales, UK \\ Correspondence: Hao Wu, Cardiff University, Cardiff, Wales, UK.
}

Received: February 10, 2020

Accepted: March 25, 2020

Online Published: April 6, 2020

doi:10.20849/abr.v5i1.733

URL: https://doi.org/10.20849/abr.v5i1.733

\begin{abstract}
The increased emphasis upon the value chain and a growing focus on value adding activities has led to several new developments in management accounting. Critically evaluate these contemporary techniques and discuss the extent to which they offer improvements compared to traditional accounting techniques. Furthermore, management accounting will improve accounting techniques when value chain and add value-adding activities develop in the enterprise that searches for new accounting skills in the operation of the company. Generally, parts of traditional accounting techniques are not suitable for use in the current field of accounting, because these traditional accounting techniques could not provide the accurate index of cost, profit, depreciation and other factors considered by managers for operation. So, this essay would discuss several new accounting techniques in order to promote the performance of management and make manager will recognize what accounting techniques they should utilize for gaining better efficient management in the future.
\end{abstract}

Keywords: new accounting techniques, traditional accounting techniques, value chain, add value-adding activities

With the globalization of business development, accounting standards and techniques have undergone tremendous changes and developments. Furthermore, advancing in value chains and value-adding activities have led to the application of new accounting techniques to different enterprises. Because Michael Porter (1985) believed that every enterprise is a collection of events in the process of designing, manufacturing, selling, delivering, and assisting its products. Therefore, under the background of the continuous surge of business competition, some accounting experts found many shortcomings from the traditional accounting techniques. So new accounting techniques could be needed to increase the competitiveness of enterprises, compared with traditional accounting techniques, in terms of 3 aspects of development form traditional accounting techniques, activity-based costing (ABC), balanced score Card(BSC), and economic value added (EVA). Advantages of ABC, BSC, and EVA have shown respectively in helping companies to focus on management, emphasize the close relationship between performance management and enterprise strategy, and set up clear directions of management. Moreover, the essay illustrates that ABC, BSC, EVA could bring more advantages than disadvantages back In the daily operation of the companies, compared with traditional accounting techniques.

First of all, the adsorbing cost (AC) was introduced by experts in various companies in the 19th century, which symbolized accounting techniques made tremendous progress. Because limited product diversification would exist at that time, and customers had no dominant power or choice in the market, the absorbing cost has been recognized as an important part of traditional costs accounting (TCA). Furthermore, traditional accounting largely focused on the direct cost of products rather than indirect cost, although AC could also involve indirect cost. For example, when the indirect cost has occupied highly total cost, AC could not explain and analyze it as a helpful accounting technique. However, Johnson and Kaplan (1987) claimed that TAC had lost the relevance of companies in the early 20th century. The strategic management accounting techniques were gradually introduced into companies when TCA could not deal with issues of accounting. In terms of cost management of value chain, the crucial aspect of $\mathrm{ABC}$ compared with traditional accounting technique was discussed by Lazar, J. (2012), Cokins, (1996, 2002), Cohen, (2000) who supported that the key aspect of ABC was to allocate resources (i.e., expenses) to activities. So the $\mathrm{ABC}$ would be more accurately find what causes high costs in operation (i.e., activities), which could be more valuable than TAC that just used machine hour or labor hour as apportion. Nevertheless, traditional accounting way would not reflect the happening reason for manufacturing cost and 
period cost truly, because this apportions cost was not accurate, which could be analyzed by Gogolova, M. et al. (2015). Firstly, the essay explains that ABC was a quantitative management method, according to the economic and technological aspects of the main characteristics of things, to utilize mathematical statistics method, statistical arrangement, and analysis for seizing the main contradiction. (Johnson and Kaplan, 1987). Furthermore, there was an example (Gogolova, M. et al. 2015) to make some differences between ABC from TCA for the calculation cost of productivity. Besides, the first advantage of ABC compared with TCA could be shown in a specific company through different accounting techniques calculating costs of product $\mathrm{A}$ and $\mathrm{B}$. Of course, the example from Gogolova, $\mathrm{M}$ would analyze between $\mathrm{ABC}$ and TCA method, leading to managers how to control cost. Additionally, not only new messages could be brought to the process of making products, but also be brought back to traditional managers. As for the pressure of competition, $\mathrm{ABC}$ could make connect with activities of processing in a company as a whole instead of calculating cost respectively to increase the company's competition. From the perspective of management, the ABC method could provide more comprehensive calculation results of costs to managers than traditional accounting method, so that the company could fully get feedback on cost management, which needed to get from the cost accounting in the value chain and value-added activities. This is why accounting technology would need to be continuously improved in value-added activities. The second advantage of ABC compared with TCA has shown in the health-care system, because of each process, the method of $\mathrm{ABC}$ had to identify cost, cost drivers, and calculate the cost of each driver. For instance, in Shahid Faghihi Hospital, there were some steps shown below:

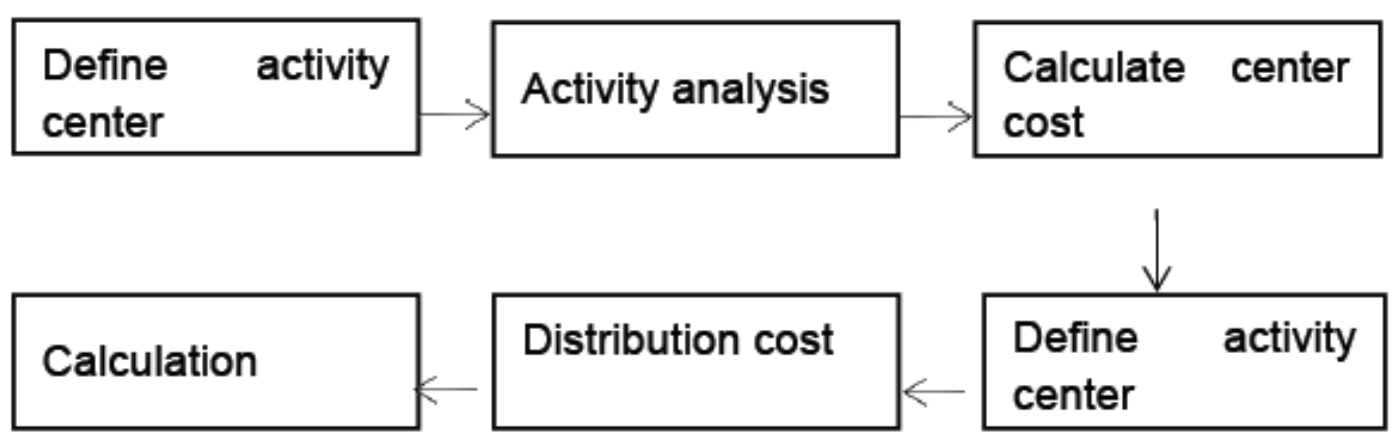

So, A Rajabi1 and A Dabiri2 (2012) probably gave the result, from their study, that the ABC method and the differences in the cost price of the electricity price method. For example, unit costs calculated based on the ABC was about $\$ 17.53$ a day, but the tariffs method calculated around \$9.94.There was a huge deviation of price, approximately \$7.6, and the study shown that all deviations were negative in the hospital for the Australian government in 2010. According to the study, the traditional method could not ultimately provide useful information and would mislead the manager. Nevertheless, compared with the traditional accounting method, ABC could need improvement in middle and small-sized enterprises (RASIAH, D. 2011). Because Drury (2000) has stated that $\mathrm{ABC}$ systems tend to be more complex than TCA, and it was expensive to operate in middle and small companies. If the costs of $\mathrm{ABC}$ exceed the benefits, the company should not apply the $\mathrm{ABC}$ system. If so, the capital expenditure of $\mathrm{ABC}$ and subsequent operating costs may become an obstacle to the enterprise, which could have negative impacts in middle and small companies. For example, Datar and Gupta (1994) argued that $\mathrm{ABC}$ 's drawback was that, by increasing the number of cost pools and improved cost base specifications, boosted the product cost measurement error of frequency. Noreen (1991) mentioned that another disadvantage was that the implementation of $\mathrm{ABC}$ was only under certain conditions to provide some useful results. McGowan and Klammer (1997) decided that another study has shown that many adopters based on ABC have given up its implementation, leading to adopters' concern about the potential impact on performance from ABC. From science, then, time-driven activity-based costing (TDABC) could be a more valuable method. To some degree, for resolution problems on traditional $\mathrm{ABC}$ through setting the TDABC model in discussing various situations, what negative or positive factors and how to resolve these factors (Patricia, E.et al. 2008) were. In traditional $\mathrm{ABC}$, the model requires a lot of specific activities, and need to make any updates when the operation changes. Besides, the TDABC would need the cost per unit of time for the entire department, compared with $\mathrm{ABC}$, that calculated activity cost rate for each task. The costs under TDABC are no longer allocated to activities but are calculated based on the resource pool (department should calculate). 
The second aspect of the development of accounting is the balanced scorecard, which was proposed by Robert s. Kaplan and David, p. NORTON (1992) to comprehensively and timely evaluate corporate performance with a set of multi-level indicators related to strategy. In addition, apart from financial indicators, managers should also consider non-financial indicators from three aspects, including the internal business process and innovation learning of customer enterprises. Because traditional accounting techniques that traditional target management system would be from setting a target to show actual performance with the calculation and analysis of the difference of the target for corrective actions, then the performance of traditional did pay attention to the control of execution process. However, the BSC emphasized balanced scorecard emphasizes that the purpose of setting performance goals would not be to control employees' behaviors, but to make employees understand the strategic mission of the enterprise, even pay for it. There are also three advantages of BSC compared with the financial performance evaluation of traditional accounting. A balanced scorecard provides strong support for strategic enterprise management and increases management efficiency. Because of the importance of establishing "twoway" communication could be recognized as the basis for effective strategy implementation in a company. (Alexander, 1985; Rapert et al., 2002). Besides, Otley (1999) has supported that special emphasis would be placed on improving useful feedback and bottom-up information. Probably, the process of creating BSC would essentially rely on a well-organized strategic appraisal and clear expression of the organization's strategic target and objectives (Kaplan and Norton, 1992, Atkinson and Brander Brown, 2001). This process itself could bring enormous value for establishing a consensus of management and increasing motivation of learning inside the company. (Neely et al., 2000). In addition, the balanced scorecard provides an effective boundary control system through the process of defining and disseminating core values throughout the organization (Mooraj et al., 1999). After that, when the BSC method clarified the causal relationship of strategy, the method also effectively transformed the strategic goal into specific goals and measures (Brander Brown and McDonnell, 1995).Moreover, Decoene and Bruggeman(2006) stated that the BSC actively supports organizational learning and reflection, encouraging interactive control through causal testing, if the BSC was implemented through definite measures and cooperative goals rather than mandatory participatory implementation. So, the BSC largely made front line managers gain greater strategy when they may face various opportunities (Beer and Eisenstat, 2000). The BSC would focus on teamwork, and improve the incentive role of enterprises and expand employees' sense of participation through establishing a rewarding system. Mohsen, M (2012) has discussed that reward would promote the performance of employees in a company, even boost their satisfaction. So, building a reward system from BSC could encourage employees to focus on teamwork, leading to employees in different departments would share information and cooperate more closed than before. Furthermore, improving the efficiency of productivity has been an important part of the development of the value chain (Laura.P2017). This is a reason why the BSC could play an important role in boosting the participation of employees, even a sense of satisfaction during value chain and value-added activity has developed, leading to improvement of productivity in the company after doing staff work closely through the rewarding system. The BSC could maximize the operation of enterprises and reduce risks. Probably, the BSC could set model such an IS system to change strategic targets to real targets. Shan Liu (2009) has discussed that the company should adopt the IS system to increase production, reducing costs, ensuring financial resources, and controlling progress. Because the IS would be affected by changes of four elements (strategy, goals, factors of risks, index of risk), and provide four steps for implementing IS: select the competitive strategy model, design strategic objectives and risk indicators, designing strategically oriented information system, design thresholds, and risk mitigation strategies. So, the IS could achieve a risk evaluation and mitigation model and translate strategic objectives into risk management execution. The model could also be reflected actual company results, and shown that the IS could be not only effective for risk assessment and mitigation information system development, but also valuable for the realization of risk, and then reduce the financial factors, customer, process, and risk in the study. By contrast, the drawbacks of the IS would be less than the advantages for the management of the company. Shan Liu (2009) argued that these factors or data could be subjective, but future studies could extend this BSC model and look at how risk indices would affect strategic objectives. Also, more risk mitigation strategies can be studied to reduce the risk of threatening strategic objectives. Finally, there are two shortages about the BSC; the one key issue that should be addressed is cost-effectiveness during companies using BSC. Another issue is that those companies consider whether BSC would bring exactly how much value to companies when the value chain has played an important role in promoting accounting techniques. (Stella, M.et al.1999).Because the cost of BSC could be expensive for middle and small size companies. Another disadvantage is that the BSC could be easily affected by cultures. For example, organizational culture may have an active or negative impact on balanced scorecard production. As Pugh (1993) generally believed that national culture and professional culture could be above organizational culture. He argued that, due to the basis of the organization, they would understand the resistance 
to the change because they were aware of the point of view of what they were doing. The organization is the alliance of interest groups in the situation of the bureau. However, in their < Building to Last > book, Collins and Poles (1994) pointed out that in practice, strengthening large organizational culture could overcome any country or job gap, and since then, employees have been surrounded by cults-like environments.

The third comparison of management accounting with traditional accounting is different economic value added (EVA) from the traditional evaluation index (i.e., ROA\&ROE). The traditional measurement of property return rate and the equity return rate was one dimension, defective, and backward. Due to the traditional measurement based on the historical data, the price of the stock return rate and the return rate of the capital stock were merely reflected in the past business, not the future business. At the same time, the traditional measurement would be restricted because the two methods reflected in the data of historical records and price. The methods suffered from increasing in the amount of information that made executor easy to handle their reports. Moreover, these measures also ignored risk factors and did not consider whether any external resources have been invested in the enterprise to generate income. If the two organizations use different database policies, old methods, or data allocation methods, according to their operations and practices in specific countries/regions, and these measures would be exposed to errors. These measures also did not take into account the cost of rights and interests and only considered interest expenses. The equity return rate has been a traditional measure of effectiveness, which could help investors determine whether the company was an efficient or inefficient company. Fundamentally speaking, it could be valuable for setting up profit-making companies and create profit-making companies, providing an indicator of profit efficiency. Then, People have found that the traditional measures have been widely used, but failed to grasp the value of the stock. As a result, companies would need a new measure of effectiveness, and the concept of EVA came into being (Ittner \& Larcker, 1998). The Gupta and Sikarwar in 2016 adopted the panel regression to test the EVA and other relative and incremental information content of accounting index based on the fixed-effects model. So, there was evidence to support the assumption that EVA had more information than accounting methods and incremental information, and the results were consistent with the existing literature.

Therefore, EVA was superior to the performance indicators of traditional accounting, and these findings were quite significant to maintain the value of corporate managers, investors, and corporate management. Eventually, the information of EVA from Gupta and Sikarwar was that it had more relevant information and incremental information than other traditional financial indicators, and EVA was related to the corrected stock return. After that, the research from Gupta and Sikarwar revealed that the EVA evaluation method should focus on the usefulness of evaluating the company's financial assets because it was consistent with the maximization of the financial wealth of the stock. In analyzing the effectiveness of financial services, companies should consider the measurement of EVA that had a significant practical meaning for the direct and access of the company's financial information (such as the management level, the board of directors, the company, the stock, the employee, the right person and the government). These developments were quite helpful to those who paid closed attention to the state of the company's finances when people would make investment decisions. So, the EVA would be more valuable than traditional accounting techniques in the value chain for an enterprise. Nevertheless, the EVA had also some drawbacks in the company. One was a short term measure, because, if EVA increased in the short term, it could decline in the future, leading to bonus based on EVA reduce (Stewart III, G B. 1991). Another was easy to manipulate because it would be affected by cynical calculation based on the biased estimation. For example, estimates of band debt or depreciation could affect the EVA.

In conclusion, this essay illustrates that the new development and progress of accounting techniques through $\mathrm{ABC}$, BSC, EVA to compare with traditional accounting techniques (AC, ROI, ROE), which shows the new improvement and progress of accounting in the development of value chain and value-added activities. Traditional accounting has existed in the enterprise accounting system for many years, but it brought more disadvantages than advantages to companies. Mainly, these advantages have been focusing on strategic management. As a result of traditional accounting, techniques paid attention to cost itself rather than matching the development speed and requirements of modern accounting techniques, method of estimating costs. There are also its limitations, and probably, the essay analyzes the development of new techniques. However, these limitations would not be solved by valuable methods in this essay. Possibly, increasing relevant researches or studies that could establish more useful models to avoid these risks form new accounting techniques, even remove these shortages form new accounting techniques. 


\section{References}

Agrawal, A., Mohanty, P., \& Totala, N. K. (2019). Does EVA Beat ROA and ROE in Explaining the Stock Returns in Indian Scenario? An Evidence Using Mixed-Effects Panel Data Regression Model. Management and Labour Studies, 44(2), 103-134. https://doi.org/10.1177/0258042X19832397

Alexander, L. D. (1985). Successfully implementing strategic decisions. Long Range Planning, 18(3), 91-7.

Atkinson, H., \& Brander, B. J. (2001). Rethinking performance measures: assessing progress in UK hotels. International Journal of Contemporary Hospitality Management, 13(3), 128-35.

Beer, M., \& Eisenstat, R. (2000). The silent killers of strategy implementation and Learning. Sloan Management Review, 41(4), 29-40.

Brander, B. J., \& McDonnell, B. (1995). The balanced scorecard: short-term guest or long-term resident?. International Journal of Contemporary Hospitality Management, 7(2/3), 7-11.

Cohen, M. D., Hawes, D. R., Hutchins, G. D., McPhee, W. D., LaMasters, M. B., \& Fallon, R. P. (2000). Activity-Based Cost analysis: A method of analyzing the financial and operating performance of academic radiology departments. Radiology, 215(3), 708-716.

Cokins, G. (1996). Activity-based Cost Management: making it Work. Irwin.

Cokins, G. (2002). Activity-based cost management: an executive's guide (Vol. 10). John Wiley \& Sons.

Collins, J. C., \& Porras, J. I. (1994). Built to Last - Successful Habits of Visionary Companies. Harper Business, New York.

Datar, S. M., \& Gupta, M. (1994). Aggregation, specification, and measurement errors in product costing. The Accounting Review, 567-591.

Decoene, V., \& Bruggeman, W. (2006). Strategic alignment and middle-level managers' motivation in a balanced scorecard setting. International Journal of Operations \& Production Management, 26(4), 429-48.

Drury, C. (2002). Management and cost accounting. London: Thomson Learning.

Gogolova, M. et al. (2015). Calculations in Managerial Accounting. https://doi.org/10.1016/S2212-5671(15)00837-0

Gupta, V. K., \& Sikarwar, E. (2016). Value creation of EVA and traditional accounting measures: Indian evidence. International Journal of Productivity and Performance Management, 65(4), 436-459.

Ittner, C. D., \& Larcker, D. F. (1998). Are nonfinancial measures leading indicators of financial performance? An analysis of customer satisfaction. Journal of Accounting Research, 36(3), 1-35.

Kaplan, R. S., \& Norton, D. P. (1992). The balanced scorecard - measures that drive performance. Harvard Business Review, 70(1), 71-9.

Keys, D. E., Azamhuzjaev, M., \& Mackey, J. (2001). Economic value added: A critical analysis. The Journal of Corporate Accounting \& Finance, 12(2), 65-71.

Laura, P. (2017). Importance of Motivation and Work Pay of Young Employees in the Value Creation Chain of a Business Company: Assessment of Changes in and Formation of Expectations. Business, Management and Education, 15(2), 211-26. https://doi.org/10.3846/bme

Lazar, J. (2012). Manazerske ucetnictvi a controlling. Grada.

Liu, S., et al.. (2009). Evaluating and Mitigating Information Systems Development Risk through Balanced Score Card. Publisher: IEEE.

McGowan, A. S., \& Klammer, T. P. (1997). Satisfaction with activity-based cost management implementation. Journal of Management Accounting Research, 9, 217-237.

Michael, G. Management Accounting: Magazine for Chartered Management Accountants. March, 77(3), p24. 2p. 1 Color Photograph, 2 Diagrams.

Mooraj, S., et al.. (1999). The balanced scorecard: a necessary good or an unnecessary evil?. European Management Journal, 17(5), 481-91.

Neely, A., et al. (2000). Performance measurement system design: developing and testing a process-based approach. International Journal of Operations \& Production Management, 20(10), 1119-45.

Noreen, E. (1991). Conditions under which activity-based cost systems provide relevant costs. Journal of 
Management Accounting Research, 159-168.

Otley, D. (2003). Management control and performance management: whence and whither?. British Accounting Review, 35, 309-26.

Patricia, E., et al.. (2008). Sanac Inc.: From ABC to time-driven ABC (TDABC) - An instructional case. Journal of Accounting Education, 26(3), 118-154.

Porter, M. E., \& Millar, V. E. (1985). How information gives you competitive advantage. Harvard Business Review, 63(4), 149-160.

Pugh, D. (1993). Understanding and managing organizational change. In C. Mabey \& B. Mayon-White (Eds.), Managing Change (2nd ed., pp. 108-112). The Open University.

Rash, D. (2011). Why Activity Based Costing (ABC) is still tagging behind the traditional costing in Malaysia?. Journal of Applied Finance and Banking, 1(1), 83-106.

Rupert, M. L., Velliquette, A., \& Garretson, J. A. (2002). The strategic implementation process: evoking strategic consensus through communication. Journal of Business Research, 55, 301-10.

Stella, M., et al.. (1999). The balanced scorecard: a necessary good or an unnecessary evil?. European Management Journal, 17(5), 481-491.

Stewart III, G. B. (1991). The quest for value. New York: Harper Collins.

\section{Copyrights}

Copyright for this article is retained by the author(s), with first publication rights granted to the journal.

This is an open-access article distributed under the terms and conditions of the Creative Commons Attribution license (http://creativecommons.org/licenses/by/4.0/). 